\title{
Implantable Cardioverter-defibrillator Therapy in the Patient with a Left Ventricular Assist Device: Still a Black Box
}

\author{
TRAVIS RICHARDSON, MD ${ }^{1}$ and CHRISTOPHER R. ELLIS, MD, FACC, FHRS ${ }^{1}$ \\ ${ }^{1}$ Vanderbilt Heart and Vascular Institute, Nashville, TN, USA
}

KEYWORDS. Heart failure, implantable cardioverter-defibrillator, left ventricular assist device, review.

\author{
ISSN 2156-3977 (print) \\ ISSN 2156-3993 (online) \\ CC BY 4.0 license
}

(C) 2017 Innovations in Cardiac Rhythm Management

\section{Introduction}

The use of implantable cardioverter-defibrillators (ICDs) has become a cornerstone in the therapy of patients with New York Heart Association (NYHA) classes II and III congestive heart failure, as randomized controlled trials have soundly established the lifesaving value of these devices. ${ }^{1-5}$ However, in patients with severe class IV NYHA symptoms or class D disease, the relative risk of sudden cardiac death compared with death from progressive pump failure decreases dramatically, and ICD therapy is not recommended in these individuals. ${ }^{6,7}$

More recently, though, the use of implantable mechanical left ventricular assist devices (LVADs) has changed the face of care for this group of patients. Since the risk of pump failure in this group is mitigated by LVAD therapy, ICD therapy has been recommended by the 2013 International Society for Heart and Lung Transplantation (ISHLT) guideline statement. ${ }^{8}$ Despite this recommendation, the exact role of ICD therapy, and the best way to program an ICD in this population, remains uncertain.

\section{ICD therapy in LVAD patients}

The principal question remaining unanswered is whether or not ICD therapy provides a survival benefit in patients with an LVAD. To date, there has been no randomized prospective evaluation of ICD therapy in this

The authors report no conflicts of interest for the published content. Address correspondence to: Christopher R. Ellis, MD, FACC, FHRS, $121121^{\text {st }}$ Avenue South, MCE-5414, Nashville, TN 37232 USA.

E-mail: christopher.ellis@vanderbilt.edu. population. Several retrospective evaluations have suggested a survival benefit for ICD therapy in patients with LVAD support, ${ }^{9,10}$ while others have not come to this conclusion. ${ }^{11-14}$ Two meta-analyses have been performed in recent years that may provide insight into the disparity of these results. One analysis performed by Vakil et al. examined six observational studies encompassing data from 937 patients, $93 \%$ of whom had LVAD therapy as a bridge to transplantation, 39\% of whom had a continuous-flow (CF) device, and $38 \%$ of whom had an ICD in place. This analysis found a relative risk of 0.61 for all-cause mortality with a confidence interval of 0.46 to $0.82(p<0.01) .{ }^{15}$ The major concern with these data is their generalizability to modern LVAD therapy, where the vast majority of patients are implanted with $\mathrm{CF}$ devices and have pre-existing ICDs in situ. As such, there is concern that the survival trend observed in this meta-analysis is likely to be confounded by a higher overall intensity of care, or by a selection bias toward patients with a better prognosis in individuals with an ICD implanted.

A second analysis by Agrawal et al. only examined patients with continuous-flow LVAD devices, including data from 292 patients, $69 \%$ of whom had an ICD implanted. ${ }^{16}$ This analysis did not suggest a survival benefit associated with ICD use, and reported an odds ratio of survival of 1.47 with ICD therapy and a confidence interval of 0.42 to 1.47 ( $p=0.45$ ). Finally, this year, Younes et al. performed a propensity score-matched analysis involving patients with LVAD listed for heart transplantation in the United Network for Organ Sharing database between 2008 and 2015. In their investigation, 


\begin{tabular}{|c|c|c|}
\hline \multicolumn{3}{|c|}{ Monitored VT Episode \#139 } \\
\hline Device: Protecta XT CRT-D D314TRG & Serial Number: PFS204921H & Date of Visit: 13-Dec-2013 11:49:28 \\
\hline$\overline{\text { Patient: }}$ & ID: & Physician: Dr. C. Ellis $615-322-2318$ \\
\hline
\end{tabular}

\begin{tabular}{|c|c|c|c|c|c|c|c|c|c|}
\hline $\begin{array}{l}\text { ATP } \\
\text { Seq }\end{array}$ & Shocks & Success & ID\# & Date & $\begin{array}{c}\text { Time } \\
\text { hh:mm }\end{array}$ & $\begin{array}{l}\text { Duration } \\
\text { hh:mm:ss }\end{array}$ & $\begin{array}{c}\text { Avg bpm } \\
\text { A/V }\end{array}$ & $\begin{array}{c}\text { Max bpm } \\
\text { A/V }\end{array}$ & $\begin{array}{c}\text { Activity at } \\
\text { Onset }\end{array}$ \\
\hline VT-Mon & & & 139 & 21-Sep-2013 & $16: 24$ & 23:32:13 & $76 / 147$ & 115/158 & Rest \\
\hline
\end{tabular}

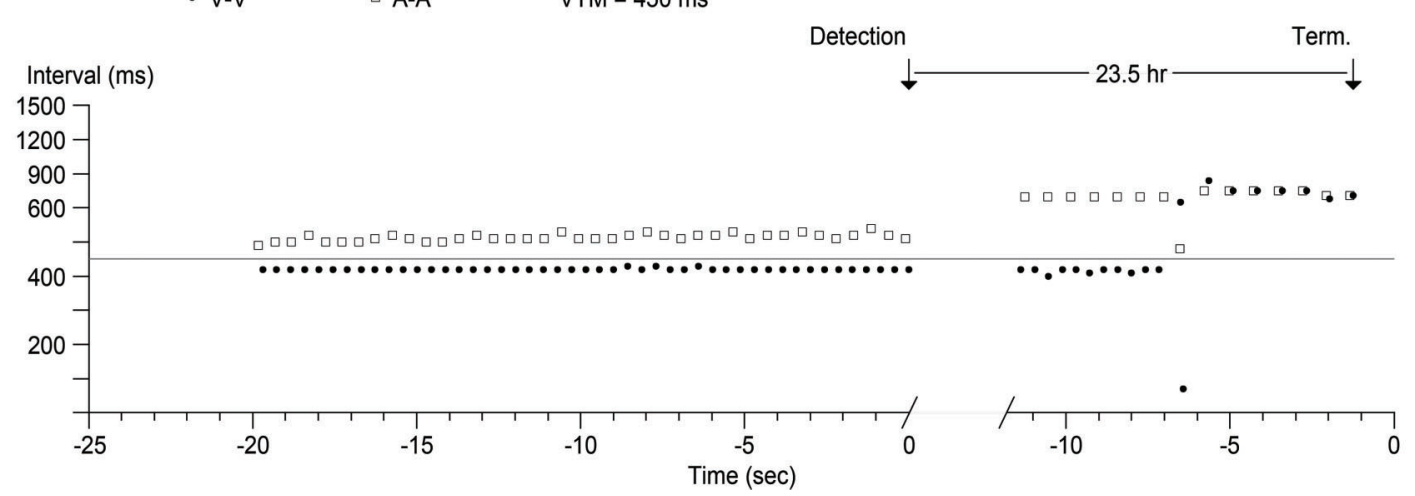

Figure 1: Intracardiac electrogram showing ventricular tachycardia sustained for 23.5 hours with spontaneous termination followed by an atrial pacing-biventricular pacing paced rhythm.

722 patients with an ICD were compared with 722 patients without ICD, and no association between decreased waitlist mortality and ICD use was found. ${ }^{17}$ In summary, while the largest analysis of available data suggests a survival benefit associated with ICD therapy in LVAD patients, more recent data that likely better represent "today's" LVAD patient do not corroborate this conclusion. Thus, we are left with uncertainty regarding the benefit of ICD therapy in these patients and, certainly in some individuals (such as those with inappropriate shocks, ventricular tachycardia storm, or cardiovascular implantable electronic device-associated infection), indications that the ICD may do more harm than good.

\section{LVAD implantation in ICD patients}

Though the role of ICD therapy remains in question, it is important to note that the majority of patients who undergo LVAD implantation already have an ICD in place preoperatively. This means that the question of proper programming in this population is possibly more germane to their care than the question of whether to implant an ICD or not. The clinical implications of ventricular arrhythmias (VAs) are seemingly clearer. In many cases, patients with LVADs who experience VA, or even prolonged asystole, will remain asymptomatic, or nearly so. ${ }^{18-20}$ A small, well-performed clinical study by the group at the Cleveland Clinic examined hemodynamic changes during defibrillation threshold testing among patients with LVADs in place who were undergoing ICD implantation. This study demonstrated a $32 \%$ reduction in LVAD flow during ventricular fibrillation, with return to normal flow with restoration of sinus rhythm. ${ }^{21}$ These findings imply that these arrhythmias do affect cardiac output, but also that LVAD therapy appears to make a life-threatening VA like ventricular fibrillation into one of non-emergent importance. With these data in mind, it seems most appropriate to think of VAs in the LVAD patient similarly to the way one might think of atrial arrhythmias in the unsupported patient with chronic heart failure. In both instances, these arrhythmias may lead to symptomatic low-output states, but in the vast majority of cases, the arrhythmia is not life-threatening.

Unlike in the patient without an LVAD, the tolerance of VAs for minutes to hours or even days, rather than seconds, is commonplace in those with LVADs (Figures $\mathbf{1}$ and 2). As such, traditional ICD programming strategies in this group seem unlikely to be appropriate; indeed, one study found that implantation of a CF LVAD was associated with changes in the performance of pre-existing ICD, including the occurrence of ICD-related adverse events. ${ }^{22}$ Another suggested electromagnetic interference between LVADs and ICDs may ultimately necessitate ICD replacement. ${ }^{23}$ Unfortunately, device company firmware restrictions in ICDs do not truly allow for appropriate LVAD programming to be employed. Currently, the longest possible programmable detection interval prior to tachytherapy delivery is in the range of 30 seconds to one minute.

In light of this, one could argue that perhaps we need to change our approach to VAs in the LVAD population drastically. It seems reasonable, in the coming years, to investigate the role of a remote monitoring strategy for VA. Detection could prompt alerts to physicians or patients and perhaps urgent, rather than device-initiated, cardioversions could be arranged. This has the potential to reduce both hospitalizations and painful ICD shocks in the LVAD population. One common theme among previously published studies is that the best predictor of appropriate ICD therapy after an LVAD is implanted 

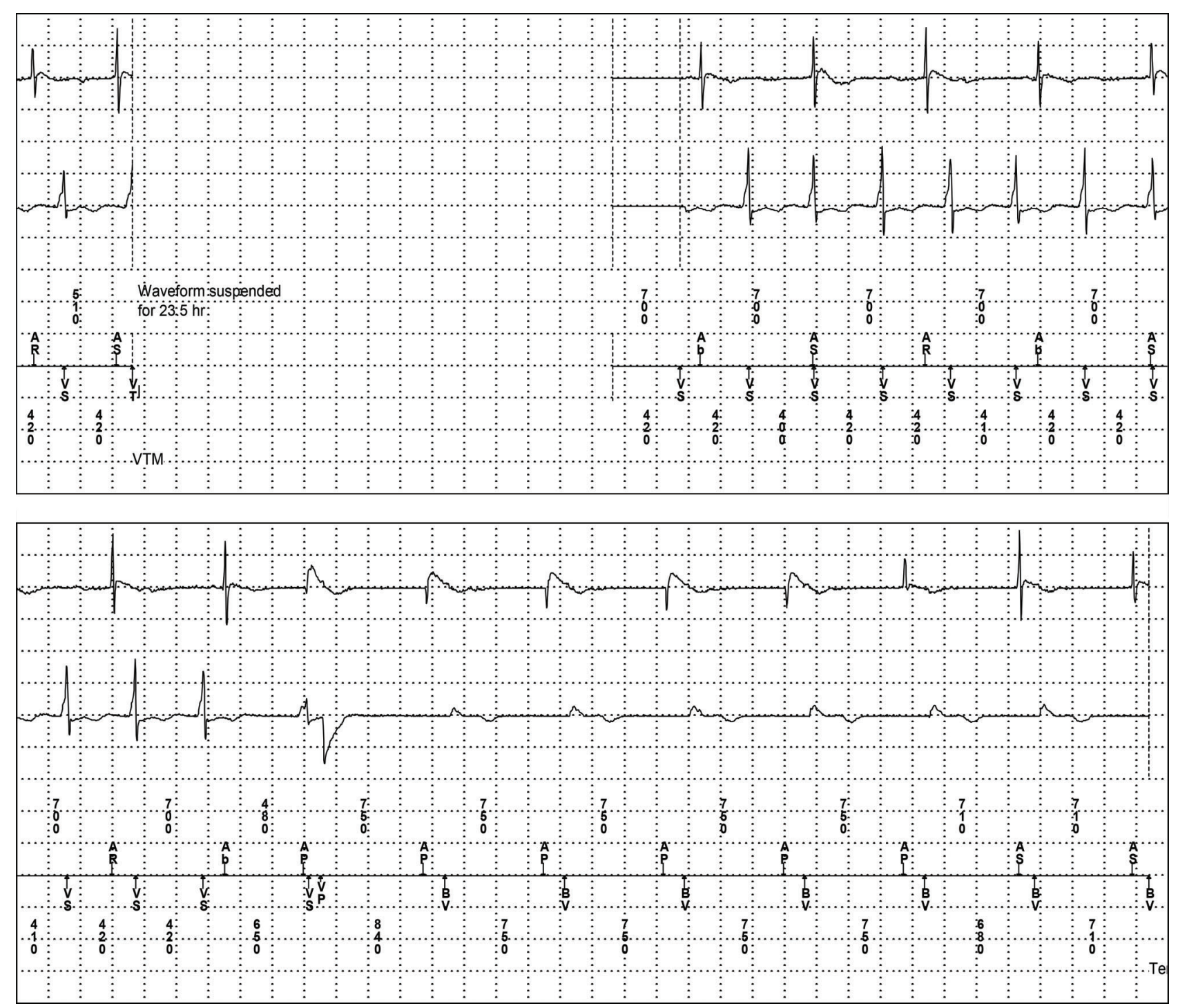

Figure 2: Intracardiac electrogram showing ventricular tachycardia sustained for 23.5 hours with termination a single premature ventricular contraction with VSR pacing.

is the presence of sustained VAs prior to implantation (ie, secondary prevention population). ${ }^{24}$

Other questions that must be considered include the potential for and the management of infection in the setting of concomitant LVAD and cardiovascular implantable electronic device implantation, ${ }^{25}$ and the safety and efficacy of LVAD implantation done in conjunction with that of newer technologies, such as subcutaneous ICDs. ${ }^{26}$ The efficacy and benefits of cardiac resynchronization therapy device use in LVAD recipients also remains a topic of interest. ${ }^{27,28}$

\section{Conclusions}

In summary, there are two important questions regarding ICD therapy in the LVAD population that remain unanswered: does ICD therapy improve survival in the LVAD patient, and how should existing ICDs be programmed in patients with LVAD therapy? Prospective, randomized investigations will be required to advance our understanding of ICD therapy in this growing population.

\section{References}

1. Bardy GH, Lee KL, Mark DB, et al. Amiodarone or an implantable cardioverter-defibrillator for congestive heart failure. N Engl J Med. 2005;352(3):225-237.

2. Moss AJ, Zareba W, Hall WJ, et al. Prophylactic implantation of a defibrillator in patients with myocardial infarction and reduced ejection fraction. N Engl J Med. 2002;346(12): 877-883.

3. Moss AJ, Hall WJ, Cannom DS, et al. Improved survival with an implanted defibrillator in patients with coronary disease at high risk for ventricular arrhythmia. N Engl J Med. 1996;335(26):1933-1940.

4. Antiarrhythmics versus Implantable Defibrillators (AVID) Investigators. A comparison of antiarrhythmic-drug therapy 
with implantable defibrillators in patients resuscitated from near-fatal ventricular arrhythmias. N Engl J Med. 1997;337(22): 1576-1584.

5. Buxton AE, Lee KL, Fisher JD, Josephson ME, Prystowsky EN, Hafley G. A randomized study of the prevention of sudden death in patients with coronary artery disease. N Engl J Med. 1999;341(25):1882-1890.

6. MERIT-HF Study Group. Effect of metoprolol CR/XL in chronic heart failure: Metoprolol CR/XL Randomised Intervention Trial in-Congestive Heart Failure (MERIT-HF). Lancet. 1999; 353(9169):2001-2007.

7. Epstein AE, DiMarco JP, Ellenbogen KA, et al. 2012 ACCF/ AHA/HRS focused update incorporated into the ACCF/ AHA/HRS 2008 guidelines for device-based therapy of cardiac rhythm abnormalities: a report of the American College of Cardiology Foundation/American Heart Association Task Force on Practice Guidelines and the Heart Rhythm Society. Circulation. 2013;127(3):e283-e352.

8. Feldman D, Pamboukian SV, Teuteberg JJ, et al. The 2013 International Society for Heart and Lung Transplantation Guidelines for mechanical circulatory support: executive summary. J Heart Lung Transplant. 2013;32(2):157-187.

9. Cantillon DJ, Tarakji KG, Kumbhani DJ, Smedira NG, Starling RC, Wilkoff BL. Improved survival among ventricular assist device recipients with a concomitant implantable cardioverter-defibrillator. Heart Rhythm. 2010;7(4): 466-471.

10. Refaat MM, Tanaka T, Kormos RL, et al. Survival benefit of implantable cardioverter-defibrillators in left ventricular assist device-supported heart failure patients. J Card Fail. 2012;18(2):140-145.

11. Enriquez AD, Calenda B, Miller MA, Anyanwu AC, Pinney SP. The role of implantable cardioverter-defibrillators in patients with continuous flow left ventricular assist devices. Circ Arrhythm Electrophysiol. 2013;6(4):668-674.

12. Andersen M, Videbæk R, Boesgaard S, Sander K, Hansen $\mathrm{PB}$, Gustafsson F. Incidence of ventricular arrhythmias in patients on long-term support with a continuous-flow assist device (HeartMate II). J Heart Lung Transplant. 2009;28(7): 733-735.

13. Garan AR, Yuzefpolskaya M, Colombo PC, et al. Ventricular arrhythmias and implantable cardioverter-defibrillator therapy in patients with continuous-flow left ventricular assist devices: need for primary prevention? J Am Coll Cardiol. 2013; 61(25):2542-2550.

14. Lee W, Tay A, Subbiah RN, et al. Impact of implantable cardioverter defibrillators on survival of patients with centrifugal left ventricular assist devices. Pacing Clin Electrophysiol. 2015;38(8):925-933.

15. Vakil K, Kazmirczak F, Sathnur N, et al. Implantable cardioverter-defibrillator use in patients with left ventricular assist devices: a systematic review and meta-analysis. JACC Heart Fail. 2016;4(10):772-779.
16. Agrawal S, Garg L, Nanda S, et al. The role of implantable cardioverter-defibrillators in patients with continuous flow left ventricular assist devices - a meta-analysis. Int J Cardiol. 2016;222:379-384.

17. Younes A, Al-Kindi SG, Alajaji W, Mackall JA, Oliveira GH. Presence of implantable cardioverter-defibrillators and waitlist mortality of patients supported with left ventricular assist devices as bridge to heart Transplantation. Int J Cardiol. 2017; 231:211-215.

18. Healy C, Viles-Gonzalez JF, Sacher F, Coffey JO, d'Avila A. Management of ventricular arrhythmias in patients with mechanical ventricular support devices. Curr Cardiol Rep. 2015;17(8):59.

19. Oz MC, Rose EA, Slater J, Kuiper JJ, Catanese KA, Levin HR. Malignant ventricular arrhythmias are well tolerated in patients receiving long-term left ventricular assist devices. J Am Coll Cardiol. 1994;24(7):1688-1691.

20. Fitzgibbon J, Kman NE, Gorgas D. Asymptomatic sustained polymorphic ventricular tachycardia in a patient with a left ventricular assist device: case report and what the emergency physician should know. J Emerg Med. 2016;50(3): e135-e141.

21. Cantillon DJ, Saliba WI, Wazni OM, et al. Low cardiac output associated with ventricular tachyarrhythmias in continuous-flow LVAD recipients with a concomitant ICD (LoCo VT Study). J Heart Lung Transplant. 2014;33(3):318-320.

22. Thomas IC, Cork DP, Levy A, et al. ICD lead parameters, performance, and adverse events following continuous-flow LVAD implantation. Pacing Clin Electrophysiol. 2014;37(4):464-472.

23. Boudghène-Stambouli $F$, Boulé $S$, Goéminne $C$, et al. Clinical implications of left ventricular assist device implantation in patients with an implantable cardioverter-defibrillator. J Interv Card Electrophysiol. 2014;39(2):177-184.

24. Efimova E, Fischer J, Bertagnolli L, et al. Predictors of ventricular arrhythmia after left ventricular assist device implantation: a large single-center observational study. Heart Rhythm. 2017 Jul 27. pii: S1547-5271(17)30895-0.

25. Riaz T, Nienaber JJ, Baddour LM, Walker RC, Park SJ, Sohail MR. Cardiovascular implantable electronic device infections in left ventricular assist device recipients. Pacing Clin Electrophysiol. 2014;37(2):225-230.

26. Gupta A, Subzposh F, Hankins SR, Kutalek SP. Subcutaneous implantable cardioverter-defibrillator implantation in a patient with a left ventricular assist device already in place. Tex Heart Inst J. 2015;42(2):140-143.

27. Schleifer JW, Mookadam F, Kransdorf EP, et al. Effect of continued cardiac resynchronization therapy on ventricular arrhythmias after left ventricular assist device implantation. Am J Cardiol. 2016;118(4):556-559.

28. Gopinathannair R, Birks EJ, Trivedi JR, et al. Impact of cardiac resynchronization therapy on clinical outcomes in patients with continuous-flow left ventricular assist devices. J Card Fail. 2015;21(3):226-232. 